Aletria, Belo Horizonte, v. 31, n. 1, p. 169-194, 2021

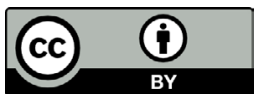

\title{
Temas e questões para uma história da edição de quadrinhos na América Latina
}

\section{Themes and Issues for a Publishing History of Comics in Latin America}

\author{
Ivan Lima Gomes \\ Universidade Federal de Goiás (UFG), Goiânia, Goiás / Brasil \\ igomes2@ufg.br \\ https://orcid.org/0000-0001-7873-8484
}

Resumo: Sob um ponto de vista histórico, encontra-se uma quantidade expressiva de revistas ilustradas, jornais, álbuns e graphic novels que permite apontar a presença marcante da história em quadrinhos na América Latina. No entanto, ela continua sendo pouco pesquisada de uma perspectiva da história editorial. Nosso ensaio buscará desenvolver temas que nos permitam pensar a materialidade dos quadrinhos na América Latina a partir de um diálogo com campos como a história do livro e da leitura. Alguns quadrinhos publicados ao longo do século XX serão tomados como estudos de casos, para discutir aspectos específicos relacionados à edição - tipografia, relação entre imagens/textos, apropriações culturais e introdução dos quadrinhos em projetos literários - com vistas a uma interpretação das peculiaridades históricas presentes nos quadrinhos da região. Consideramos possível apontar que tais elementos são fundamentais para o estabelecimento de uma expressão latino-americana dos quadrinhos a partir de uma abordagem transnacional.

Palavras-chave: quadrinhos; história editorial; tipografia; imagem; literatura latinoamericana.

Abstract: From a historical perspective, there is an expressive quantity of illustrated magazines, newspapers, albums and graphic novels that make it possible to point out the presence of comics in Latin America. But it remains under-researched from a publishing 
history perspective. Our essay will seek to develop themes that allow us to think about the materiality of comics in the region, in a dialogue with fields such as the history of books and reading. Some case studies of comics published throughout the 20th century will be discussed based on publishing aspects - typography, the relationship between images/ texts, cultural appropriations and the introduction of comic strips in literary projects to seek out an interpretation of the historical peculiarities of comics in the region. In conclusion and from a transnational approach, we consider it possible to point out that such elements are central for the establishment of a Latin American expression of comics.

Keywords: comics; publishing history; typography; image; Latin American Literature.

\section{Introdução}

Fenômeno associado à diversificação dos impressos e ao advento de novas tecnologias de impressão e edição de fins do século XIX (SMOLDEREN, 2009), as histórias em quadrinhos (HQs) foram editadas em suportes distintos, como a imprensa periódica e a revista. No mundo contemporâneo, as novelas gráficas e livros para colecionadores introduzem novas questões para as relações entre HQs e impressos. Atualmente um leitor poderá encontrar quadrinhos mais próximos a livros de arte em grandes livrarias e editados em formatos especiais voltados para colecionadores, contando com um público de aficionados que se dispõe a pagar um elevado preço por tais publicações. As distintas formas de editar HQs são indicativas da sua historicidade enquanto prática cultural, enquanto que as múltiplas denominações apontam para una história da circulação dos impressos. Comics, bande dessinée, mangá, história em quadrinhos, historietas: muitos são os nomes para a prática cultural que articula imagens a palavras e símbolos gráficos. Porém, todas querem dizer a mesma coisa?

Se as primeiras pesquisas sobre HQs enveredaram na busca por responder à questão "o que são os quadrinhos" e avançaram rumo a definições formais que descobriam HQs em expressões visuais tão remotas como as pinturas rupestres ou a Coluna de Trajano, perspectivas teórico-metodológicas mais recentes apontam para outros caminhos. Busca-se mais compreender as apropriações e circulações históricas que atravessaram as HQs num dado contexto desde uma perspectiva do estudo das suas condições materiais de produção, circulação e consumo. Para tanto, os estudos em História do Livro e da Leitura apontam sugestivos 
caminhos que possibilitam melhor situar as HQs na problemática mais ampla de uma história dos impressos na Modernidade.

Na história dos impressos, as HQs são uma forma de comunicação que se consolida em fins do século XIX, a partir da confluência de fatores tais como a massificação da leitura periódica com a moderna imprensa de massas, a segmentação dos impressos, o crescimento no público leitor e o incremento trazido pela chegada de novas tecnologias (MOLLIER, 2008). Este último ponto refere-se, mais precisamente, ao aumento da tiragem de um periódico, ao amplo uso de cores e à maior interação entre imagens - isso para não mencionar os inúmeros dispositivos em torno do olhar que proliferaram ao longo do século XIX, igualmente relevantes para pensarmos numa tecnologia do olhar (CRARY, 2012, p. 99-133). As HQs representam uma inovação no interior de uma história mais longa dos impressos, onde se intensifica o predomínio da visão como sentido predominante que orienta nossa relação com o mundo (MCLUHAN, 1962).

Também fazem parte desta história as relações ambíguas vez ou outra estabelecidas com as tecnologias de edição de impressos - pensadas aqui dentro de um circuito comunicacional mais amplo, seja via Robert Darnton, seja via Thomas Adams e Nicholas Barker. Em linhas gerais, a ideia de circuito comunicacional, conforme desenvolvida por Darnton (1990), busca dar conta dos diversos agentes - autores, editores, leitores, entre outros - envolvidos diretamente na construção de sentidos que dota o livro de significação social e cultural e permite elaborar uma espécie de "biografia dos livros" (DARNTON, 1990, p. 111). Inicialmente formulado para abranger a produção de livros entre 1500 e 1800, o circuito proposto por Darnton inspirou uma série de crítica e revisões, discutidas pelo próprio autor num segundo momento (DARNTON, 2008, p. 155-169). Uma das revisões mais originais foi desenvolvida por Adams e Barker (1993, p. 5-43), que ponderavam o fato de o circuito de Darnton dialogar mais diretamente com as preocupações de um historiador social, preocupando-se mais com a história da comunicação e menos com a história dos livros - ou, como preferem chamar, dos "documentos bibliográficos" - e sua lógica, por vezes, "randômica" e que vai além das expectativas iniciais de seus agentes. Por isso, Adams e Barker (1993) destacam processos mais diretamente ligados ao universo do livro, como edição, produção, distribuição, recepção e sobrevivência.

Pensar as HQs desde seus suportes de publicação - jornal, revista, livro etc. - implica partir de problemas comuns ao universo editorial 
desde a lógica da materialidade, tais como as interações entre imagem e texto, formas de publicação, circulação e leitura. Tal opção teóricometodológica introduz novos olhares para discutir a historicidade das HQs enquanto prática cultural que se desenvolve no tempo e no espaço. Vamos explorar tais discussões a partir de alguns estudos de caso latinoamericanos. A abordagem procura pensar formatos variados associados à linguagem das HQs - tiras cômicas e revistas em quadrinhos, como exemplo -, assim como suas articulações mais explícitas com o mundo dos livros a partir de um recorte específico em torno da América Latina, o que possibilita abordar processos ligados à adaptação, tradução e apropriação cultural desde a ótica das transferências culturais (ESPAGNE, 2013). A reflexão segue uma perspectiva assumidamente panorâmica, buscando apontar algumas das abordagens possíveis para $\mathrm{o}$ estudo das HQs a partir dos debates suscitados pelos campos da história do livro e da leitura.

\section{Transferências culturais: apropriações e tensões tipográficas (1900- 1920)}

Definir as HQs a partir da presença ou da ausência de elementos formais será interpretação assumida por muitos estudos dedicados ao tema. É o debate acerca da "verdadeira origem" das HQs, que alega serem elas como que herdeiras de outras manifestações tão variadas no tempo como pinturas rupestres, hieróglifos egípcios e inscrições pré-colombianas, por exemplo. Em comum, a presença de imagens que devem ser "lidas" em série, o que ajudará a consolidar a expressão "arte sequencial" como abordagem conceitual, a qual segue sendo adotada até hoje por segmentos da imprensa e alguns especialistas (EISNER, 1985; MCCLOUD, 1994). Porém, tal noção perde de vista as especificidades técnicas e culturais que devem ser associadas às HQs e que se originam a partir de novas tecnologias e recursos visuais desenvolvidos durante o século XIX. Acaba servindo antes como estratégia de legitimação social de uma expressão visual historicamente desvalorizada pela crítica cultural.

Ainda segundo tal interpretação, as HQs teriam surgido não nos EUA, mas sim na Europa a partir do artista suíço Rodolphe Töpffer. Publicada em 1833, Histoire de M. Jabot continha imagens em série acompanhadas de legendas, o que lhe permitia definir seu trabalho como littérature en estampes. Tomando esta premissa como base, torna-se 
possível descobrir novos pioneiros das HQs em outros países. Listá-los seria longa tarefa; entre outros, vale destacar aqui a obra de Angelo Agostini. É considerado por parte da bibliografia brasileira como o "pai dos quadrinhos brasileiros" por seu trabalho intitulado As aventuras de Nhô Quim ou Impressões de uma viagem à corte (1869), ao ponto de o principal prêmio dedicado às HQs brasileiras levar seu nome. De origem italiana, viveu infância e adolescência em Paris e migrou para o Brasil com dezesseis anos. Logo se tornaria um dos mais importantes artistas do Império brasileiro. Em relação às HQs, Agostini se destaca por ter atuado nos anos iniciais da revista infantil ilustrada $O$ Tico-Tico (GOMES; GONÇALVES, 2016, p. 225-240), que introduziu no Brasil diversas tiras cômicas de sucesso nos EUA do início do século XX, como Little Nemo in Slumberland (1905), de Winsor McCay e Krazy Kat (1913-1944), de George Herriman.

Enquanto a controversa reivindicação do nome de Angelo Agostini como patrono das HQs segue forte nas memórias dos entusiastas brasileiros desta linguagem, ${ }^{1}$ manifestações gráficas próximas às HQs podem ser encontradas em revistas e jornais já nas primeiras décadas do século XX. Desde 1905, O Tico-Tico lançava adaptações brasileiras para Buster Brown, tira criada por Richard Outcault. Seu sucesso foi tamanho que o personagem - conhecido no Brasil como Chiquinho cresceu no interior da revista: ganhou novas histórias, um universo de novos personagens, ausentes da versão original, e chegou à adolescência. Chiquinho torna-se o símbolo da revista (GONÇALVES, 2019, p. 17-36).

A circulação das HQs para além dos EUA se deve, em grande medida, aos syndicates, agências distribuidoras especializadas em produzir e distribuir HQs. O rápido sucesso comercial e de público das HQs desde fins do século XIX não mais comportaria apenas o público consumidor estadunidense; rapidamente regiões como Europa e América Latina se tornaram consumidoras de comics. Se uma série de tiras cômicas de Mutt and Jeff(1907-1983), de Bud Fisher, atestava que grandes acontecimentos desenrolados ao sul do Rio Grande, como a Revolução Mexicana, não

\footnotetext{
${ }^{1}$ Dentre os muitos trabalhos que se dedicam a reivindicar Agostini como o primeiro autor de quadrinhos brasileiros, destacam-se a obra de Gilberto Maringoni (2011), resultado de sua tese de doutorado, e artigo de Cagnin sobre algumas etapas de suas investigações inconclusas em torno de Agostini (CAGNIN, 2013, p. 53-73). A presença de Agostini no panteão de autores brasileiros de HQ está longe de ser inocente e aponta para disputas de sentido sobre os quadrinhos no país (GOMES, 2021, no prelo).
} 
podiam mais ser ignorados nem mesmo pelas HQs, estas também não poderiam deixar de lado o público leitor para além das fronteiras dos EUA. Em fins dos anos 1960, o teórico belga Armand Mattelart destacou que um syndicate como King Features Syndicates conseguia traduzir seus comics para mais de 30 idiomas e publicá-las em mais de 100 países e em mais de cinco mil periódicos (MATTELART, 1970, p. 139).

As HQs publicadas n'O Tico-Tico oferecem exemplos interessantes quanto às tensões presentes no interior do formato. Tal como revistas ilustradas franco-belgas do início do século demonstravam resistência quanto ao uso do balão de fala (LEFÉVRE, 2006), as HQs publicadas n'O Tico-Tico sofriam intervenções diretas dos seus editores. Suprimiam-se balões de fala, substituídos por legendas, na tradição visual difundida por nomes ligados à técnica litográfica, como Rodolphe Töpffer e, no Brasil, Angelo Agostini. Num primeiro olhar, trata-se apenas de uma edição sem maiores consequências, ou seja, um problema menor em relação ao enredo presente na sequência de quadros. Porém, revela que a introdução de uma forma de narrar com soluções gráficas e visuais próprias não se dava sem estranhamentos. As diferenças ficam nítidas.

FIGURA 1 - Quadro comparativo entre Buster Brown [detalhe], de Richard Outcault, e As desventuras do Chiquinho: uma viagem [detalhe], sem autoria creditada
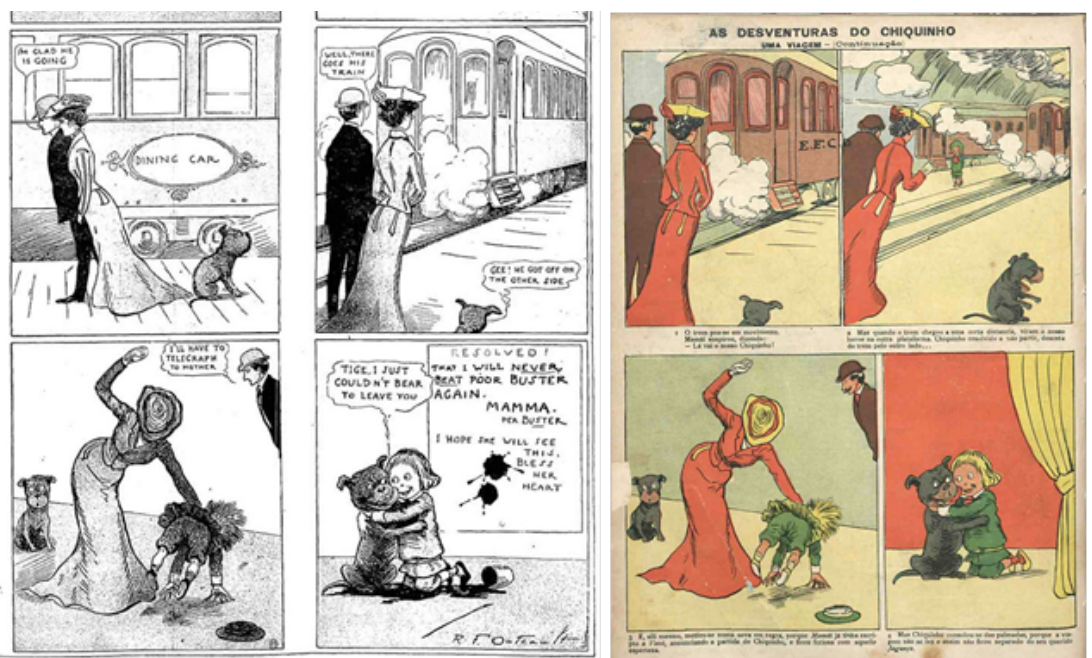

Fonte: respectivamente, New York Herald, 1903; O Tico-Tico, 1906 (apud SILVEIRA, 2013). 
As imagens acima, levantadas a partir de indicação presente em artigo de Guilherme Silveira (2013), são interessantes não apenas por explicitarem as operações de decupagem e adaptação que levam o personagem Buster Brown a tornar-se Chiquinho, mas por indicarem as relações entre transferências e adaptações culturais e edição. Na versão d'O Tico-Tico, os personagens são silenciados e, no seu lugar, surge um narrador onipresente a conduzir a história, o que, a um só tempo, retira parte da força da narrativa visual presente em Buster Brown e a insere no universo da fábula e da literatura voltada para crianças. De acordo com Silveira, na HQ brasileira o narrador inicia a história com "Há muito tempo já vovó tinha escrito a mamãe, pedindo que mandassem Chiquinho para passar uns dias com ela na roça". Já em Buster Brown, não há indicação de quando foi combinada a viagem de Buster Brown, apresentando-se no cabeçalho um telegrama que seu pai enviara à avó, comunicando-a sobre a viagem do personagem-título. Além disso, um funcionário negro da companhia ferroviária torna-se, em Chiquinho, um criado da família. Do telegrama que desaparece à "roça", passando pelos novos lugares dados a personagens negros, as adaptações pelas quais passou Chiquinho permitiram melhor situá-lo na realidade brasileira, numa publicação voltada para crianças brancas de cidades que se pretendiam modernizadas, como o Rio de Janeiro.

O balão parecia ser um problema sério para O Tico-Tico. Em alguns casos, pareceu inevitável mantê-los, mesmo que esvaziados de textos. Com as legendas, Gato Félix torna-se um personagem verborrágico, sempre com algo a dizer a cada quadro. 
FIGURA 2 - As proezas do Gato Félix, a partir de original de Pat Sullivan

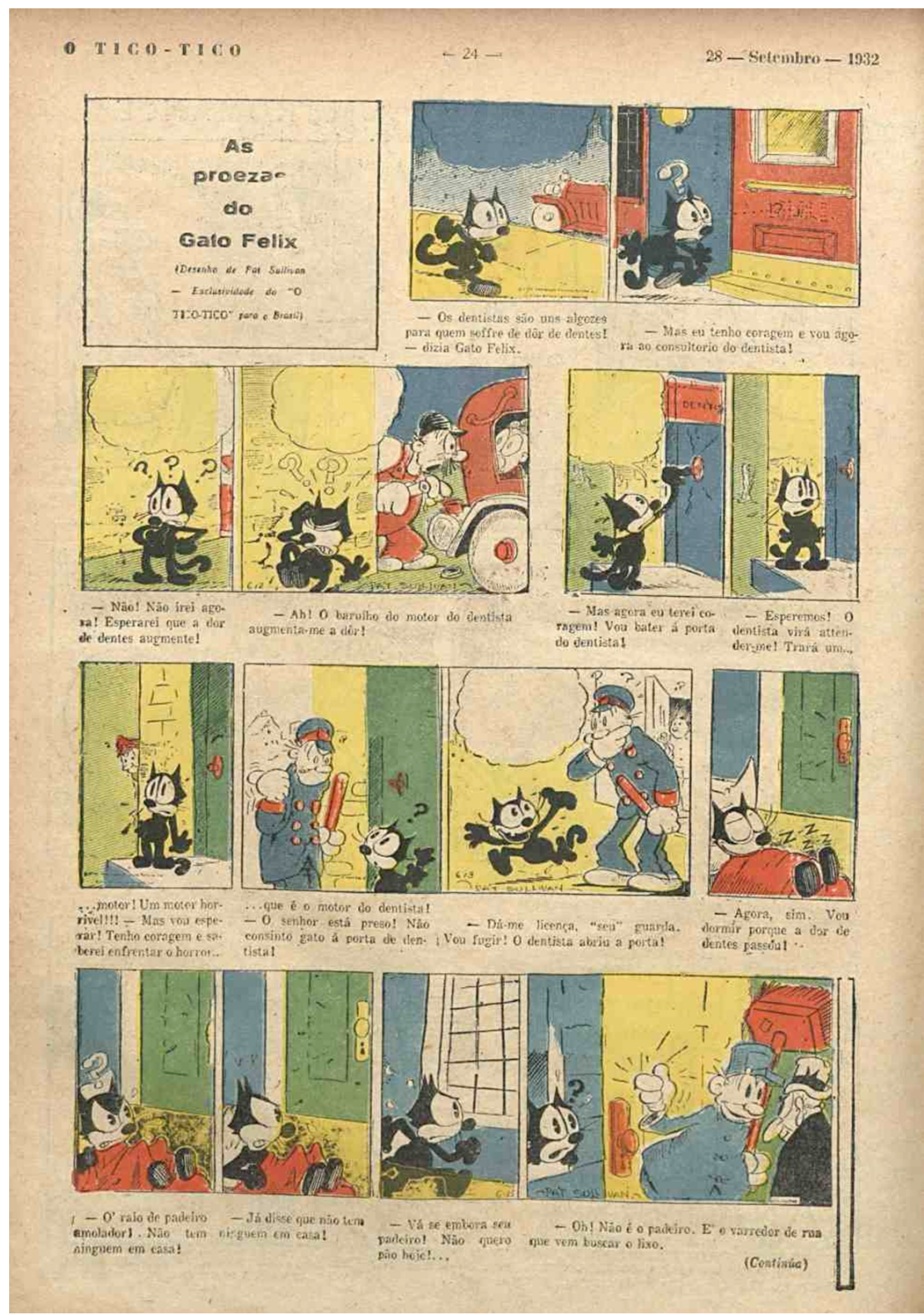

Fonte: O Tico-tico, Rio de Janeiro, n. 1408, 28 set. 1932. Disponível em: http:// memoria.bn.br/pdf/153079/per153079_1932_01408.pdf. Acesso em: 30 ago. 2020. 
Num momento em que ainda não havia muita clareza quanto ao fato de as HQs serem arte, criação autoral ou simplesmente um entretenimento para impulsionar vendas de jornais, apropriações culturais sobre elas parecem ter sido procedimento comum. No México, outra tira cômica dos EUA, Happy Hooligan (1900-1932), criada por Frederick Opper, torna-se Aventuras del papá de Pancholín quando publicada a partir de 1917 no jornal mexicano El Universal. Se em Happy Hooligan temos um personagem principal que, mesmo levando uma vida sofrida, é um feliz membro das classes mais baixas da sociedade norte-americana, Aventuras del papá de Pancholín dedica-se a narrar a busca de um pai, Panchito, por seu filho, Pancholín, ele próprio um personagem que protagonizara uma HQ - Travesuras de Pancholín, do mexicano Dax publicada neste mesmo jornal durante os primeiros meses de 1917. Se Travesuras de Pancholín buscava filiar-se à literatura europeia, de modo que suas aventuras não fossem "uma grotesca imitação do raciocínio obscuro dos EUA", Aventuras del papá de Pancholín representou a entrada dos comics no periódico, ainda que, neste caso, ao preço de uma profunda operação de adaptação aos novos ares: seus enredos e balões de fala passaram a fazer menções diretas a aspectos culturais e cotidianos da vida mexicana daqueles tempos (EFRAÍN GRANADOS, 2013, p. 27-31).

Em outro periódico mexicano das primeiras décadas do século XX também foi possível encontrar intervenções em balões de fala. Tal como n'O Tico-Tico, elas ocorreram em graus variados, passando da supressão e da opção pela legenda à inserção de texto em espanhol a partir da tipografia adotada pelo próprio jornal - e, portanto, sem o grafismo espontâneo que marcavam, então, as tiras cômicas oriundas dos EUA. Alguns casos, porém, foram mais drásticos, como no caso de uma HQ intitulada En El Garage, originalmente produzida por Gene Ahern e publicada nos EUA como Otto Auto. 
FIGURA 3 - En el garage

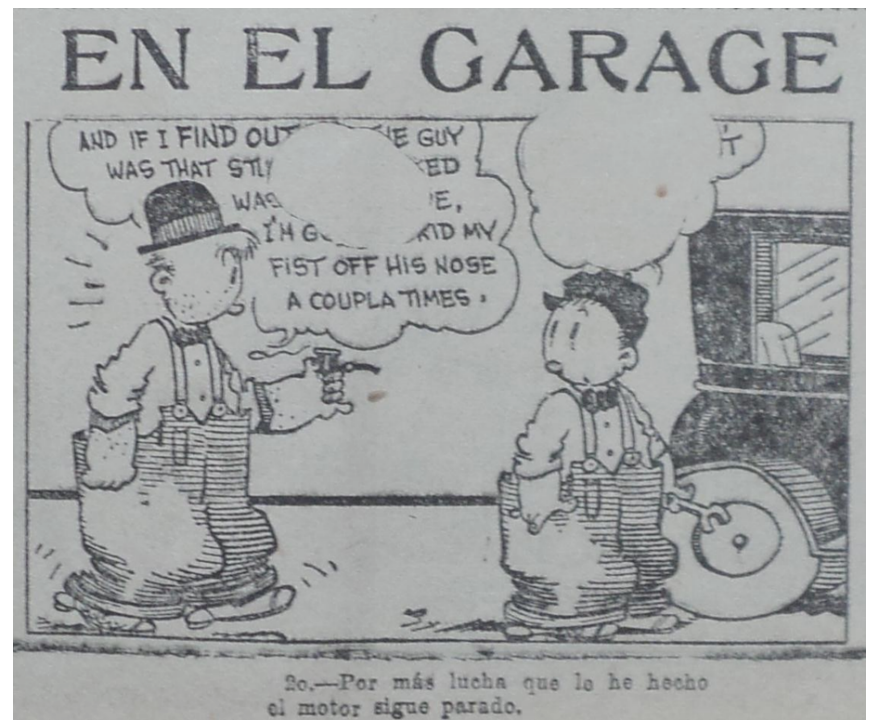

Fonte: El Heraldo de México, 21 de abril 1921, p. 11 (apud EFRAÍN GRANADO, 2013, p. 39).

Outro caso de apropriação cultural ocorre com a série Bringing up father (1913-2000). A HQ de George McManus tratava com humor, assim como tantas outras HQs, as experiências de imigrantes nos EUA. No caso, o casal de irlandeses Jiggs e Maggie enriquecem rapidamente e enfrentam todo tipo de dificuldades para se adaptarem à nova realidade. Já na América Latina, Bringing up father contribuiu para representar a modernidade urbana das primeiras décadas do século XX e a ascensão de setores médios em diversos países. No Brasil, o casal Jiggs e Maggie tornou-se conhecida como Pafúncio e Marocas; no Chile, foi publicada em 1922 por El Mercurio como Amenidades Del Diario Vivir o Educando A Papá, com o casal de personagens traduzido como Don Fausto e Crisanta. O primeiro irá servir de título para filme e importante revista que publicou HQs e ilustrações entre 1924 e 1964; e Crisanta se tornará sinônimo de mulher que domina seu marido, preferencialmente portando um rolo para massas (MONTEALEGRE, 2008, p. 203-204). Na Argentina, foram publicados pelo jornal La Nación sob o título Pequeñas Delicias de La Vida Conjugal. O casal foi renomeado como Trifón e Sisebutas e alcançou grande êxito, inspirando uma adaptação 
bem sucedida para o teatro e algumas canções, como Sisebuta y Don Trifón, um "charleston humorístico" composto por Modesto Papávero em 1925. Um trecho da letra descrevia a esposa de Don Trifón nos seguintes termos:

\author{
Sisebuta com seu empenho \\ De ser dona do lar \\ Com especial dedicação \\ Quer a seu esposo modelar. \\ Sisebutas há aos milhares \\ Se você quiser encontrará \\ Pois a mulher na atualidade \\ É uma autoridade! \\ Ela manda e nada mais ${ }^{2}$
}

(apud GARCÍA; ROCA, 2003, p. 125-136, tradução nossa).

Ao discutir dispositivos e procedimentos ligados à produção de textos e livros, Chartier propõe abordá-los separadamente, refletindo, de início, sobre as instruções mais ou menos claras formuladas por autores - as chamadas "estratégias de escrita" - e, num segundo momento, os procedimentos de produção de livros. Mais interessante ao nosso estudo é pensar, a partir de Chartier, como a maquinaria tipográfica pode sobrepor sentidos àqueles concebidos, a princípio, pelo autor e, assim, apontar para leituras e recepções distintas daquelas inicialmente previstas pelos autores de uma obra (CHARTIER, 2011, p. 96-97).

\title{
Edição e política: para rir do imperialismo cultural dos comics (1940-1970)
}

Uma mudança importante na história das HQs veio nos anos 1930, a partir da ideia de alguns distribuidores em dobrar um suplemento de jornal e vendê-lo como uma revista. A solução barata e sem maiores preocupações em adaptar as técnicas de impressão ao novo formato fizeram com que tais revistas contassem com qualidade sofrível do

\footnotetext{
${ }^{2}$ No original: "Sisebuta con su empeño/de ser dueña del hogar/con especial dedicación/ quiere a su esposo modelar./Sisebutas a millares/si usted quiere encontrará/pues la mujer en la actualidad/es un autoridad!/Ella manda y nada más. (apud GARCÍA; ROCA, 2003, p. 125-136).
} 
ponto de vista gráfico. As cores tinham que ser primárias e berrantes para aparecem bem e as letras eram de difícil leitura. Tudo isso levava a uma seleção pouco rigorosa de histórias de qualidade - mesmo porque não eram muitos os que queriam se vincular a tal mídia - que mais aproximavam tais revistas da literatura pulp. De diversão em quatro cores, quando publicados em revista os quadrinhos logo passariam a ser chamados de "pesadelos em quatro cores" por jornalistas, pedagogos e outros críticos das limitações editoriais do formato de revistas (GABILLIET, 2005, p. 1-8). E nascia também a moderna indústria de revistas em quadrinhos, com seu personagem-ícone: Superman, criado em 1933 por Jerry Siegel e Joe Shuster. O personagem só conseguiu tornarse um sucesso de público quando publicado em revistas; anteriormente, seus autores tentaram publicá-lo como tiras, sem sucesso.

A diferenciação entre comic strips e comic books era bem clara nos EUA, vide o interessante caso da HQ The Spirit (1940), de Will Eisner. Tratava-se de um super-herói que, ao contrário do que ocorreria com Superman, Batman e outros, não seria importunado pelos críticos que se seguiram às vendagens cada vez mais expressivas das revistas em quadrinhos. Por quê? Segundo Eisner, The Spirit era uma revista de super-herói publicada como suplemento dominical de jornais, o que o tornava "limpo" em relação à "suja e miserável turba que estava fazendo quadrinhos [em revistas]" (EISNER et al., 2004, p. 120). Ao serem publicados fora dos EUA, nem sempre tal associação entre superheróis e formatos de edição ficou clara, vide o caso latino-americano. É curioso notar que os super-heróis ingressaram no mercado de impressos em alguns países da América Latina em paralelo a outros heróis carentes de atributos "super-heroicos" e de gêneros tão distintos como detetive, aventuras na selva e ficção científica, sendo publicados em suplementos específicos que começaram a veicular nos jornais apenas durante os anos 1930. As primeiras editoras dedicadas a revistas em quadrinhos ou surgem no pós-Segunda Guerra, como no caso da brasileira Editora Brasil-América Limitada (EBAL, 1945-1995) e da mexicana Editorial Novaro (1948-1985); ou se estabelecem a partir deste período, como Editorial Columbia (1928-2001) na Argentina. Tal opção editorial em publicar heróis e super-heróis de forma indiscriminada em revistas levou a configurações específicas quando comparadas ao cenário norteamericano. Vejamos as publicações da brasileira EBAL. Seus primeiros super-heróis publicados numa revista própria saíram em 1945, num título 
chamado Herói. Dois anos depois, a editora publicava a revista Superman. Na capa, o conhecido super-herói era acompanhado por Batman e Robin. Porém, curioso é o editorial apresentando a revista. Ele aponta que Superhomem é um dos "Superman", ao lado de Batman, Joel Ciclone - nome adotado para o personagem Flash - e outros personagens mais ou menos dotados de superpoderes.

Ao longo dos anos, a classificação de Superman passou a incluir não apenas Batman e Super-homem, mas outros títulos como Dick Tracy (1931) e Mandrake The Magician (1934). Num certo nível, é como se todos contassem com o mesmo poder: o poder do império norteamericano. Os EUA se tornavam uma espécie de Kripton, terra de origem do Superman, tendo como sucursal latino-americana o México. Ao longo dos anos 1940-50, a região foi dominada por publicações oriundas de lá que mantinham, por meio da Editora Novaro (então Editora SEA), um acordo especial com os syndicates de quadrinhos que incluía direito à ampla distribuição do seu material a outros países americanos de língua hispânica. De acordo com o intelectual chileno Manuel Jofré (1983, p. 62), a Editora Novaro era "[...] uma instituição chave dos aparelhos hegemônico-ideológicos dos Estados Unidos, utilizados para expandir na América Latina a adesão aos EUA".

À entrada massiva de comics na América Latina, seguiram-se as críticas ao imperialismo cultural das HQs norte-americanas. Inúmeros são os exemplos de novas HQs que questionam de variadas maneiras o predomínio cultural dos quadrinhos dos EUA que se estabelece a partir do pós-Segunda Guerra Mundial. Uma das críticas mais duras desenvolveuse no interior das publicações da editora chilena Quimantú, associada ao governo socialista da Unidad Popular (1970-1973).

O traço simples, a abordagem paródica e crítica em relação ao cânone super-heroico e o contraste entre fantasia e realidade seriam recursos trabalhados na HQ da Quimantú intitulada Año 2.200. Desenhada por Guidú a partir de roteiros do filósofo e escritor Saúl Schkolnik, era um quadrinho de ficção científica que se alimentava do imaginário da Guerra Fria em torno da corrida espacial para tecer comentários sobre a realidade chilena. Uma HQ publicada no terceiro número da revista em quadrinhos Cabrochico, principal iniciativa do gênero promovida pela editora, teve como tema o papel do super-herói na vida das crianças de um planeta distante. Após um chamado de alerta, os personagens Gagarito, Próton e companhia aterrissam sua nave e se veem às voltas com uma 
cena inusitada: inspiradas num personagem chamado Super-Super - clara referência paródica a Superman -, algumas crianças do planeta visitado por Gagarito e amigos se atiram de uma pedra em direção a uma árvore na esperança de voar e, assim, salvar um gatinho que não conseguia descer do topo da árvore (CABROCHICO, 1971a, p. 10). As sucessivas tentativas fracassam, e no rosto das crianças veem-se expressões de frustração, além de hematomas. Mesmo após a realidade provar a falácia dos contos super-heroicos, os meninos seguem fiéis ao super-herói, a ponto de atacarem a pedradas Gagarito e seus amigos, que afirmam que Super-Super não passa de um “conto". O poder de Super-Super fica claro para os protagonistas quando constatam a sua presença em todo lugar: isso explica por que as crianças pensam apenas no super-herói como a solução para todos os problemas.

Presentes não só nas revistas em quadrinhos, como também em programas de TV, anúncios publicitários e monumentos públicos, os super-heróis encarnariam um "lugar de memória" incômodo para o projeto socialista de emancipação humana. Contra a individualização das ações, o trabalho em equipe defendido por Cabrochico traz o desfecho da narrativa: quando um dos garotos, ao realizar mais um salto, machuca a cabeça e precisa de socorros médicos, os personagens chilenos prontamente atendem, e então propõem a cooperação coletiva como uma estratégia para, juntos, alcançarem o mascote. Os meninos, por fim, constatam que não precisam mais de Super-Super para solucionar seus problemas e agradecem aos protagonistas, que partem de volta ao espaço.

A redução cômica do mundo das HQs de super-heróis e de seus leitores foi uma exceção dentro do projeto editorial da Quimantú, mas deve ter agradado os editores de Cabrochico, que retomaram um dos quadros/vinhetas da HQ num suplemento voltado para os pais. Esse suplemento foi publicado no quinto número de Cabrochico. Nele, os editores argumentavam a favor da proposta da revista, foi concebido como resposta à repercussão dos primeiros exemplares distribuídos, medida pelas cartas enviadas à editora (CABROCHICO, 1971b, p. 22-23). O objetivo era explicar a eles a proposta política da revista que, em suas quatro primeiras edições, não medira esforços na desconstrução crítica de diversas narrativas e personagens que habitavam o imaginário social das crianças chilenas.

O texto do suplemento começa por uma crítica aos contos de fadas tradicionais, comparando-os às HQs de super-heróis. Ao falar sobre estas 
últimas, os editores da revista questionam os pais sobre se realmente as crianças deveriam acreditar que um homem sozinho tem condições de solucionar todos os problemas do "país e do mundo" ou se, ao contrário, as dificuldades de cada um não deveriam ser solucionadas por meio da cooperação. Em vez de endossar o individualismo dos super-heróis, os pais deveriam apoiar narrativas que incentivassem a "união de todos os chilenos para o progresso do país", mostrando aos filhos "que é melhor ajudar uns aos outros, como nós, adultos", em vez de ficar esperando pelo Superman (CABROCHICO, 1971b, p. 33). Na sequência, o suplemento problematiza o etnocentrismo presente em uma HQ da Disney, que tratava os "estúpidos nativos" de forma depreciativa, não deixando de lado as críticas às HQs de terror, por seu conteúdo considerado moralmente degradante e violento. No lugar dessas histórias, deveriam ser estimuladas HQs que primassem pela cooperação e que ressaltassem o papel do trabalho e do esporte na formação sadia da criança chilena, como se vê na HQ de ficção científica Año 2.200. (CABROCHICO, 1971b, p. 30-35).

$\mathrm{O}$ suplemento faz menção direta às discussões sobre os sentidos dos quadrinhos que povoavam a imprensa e os debates acadêmicos sobre o tema desde meados dos anos 1960 no Chile. Ao lado de Para leer al Pato Donald, o livro Superman y sus amigos del alma fornece um conjunto significativo de dados produzidos a partir do debate acerca do lugar das HQs no Chile socialista. Resultado de pesquisas realizadas no interior da Quimantú entre 1971 e 1972 e publicado em 1974, na Argentina, foi escrito por Ariel Dorfman em parceria com o sociólogo Manuel Jofré. Quando do golpe que levou à derrocada da UP, o livro se encontrava em fase final de produção, pronto para encadernação e com o título inicial de "Documentos secretos sobre a vida íntima do SuperHomem e seus companheiros d'alma" (DORFMAN; JOFRÉ, 1974, p. 16), que remete ao livro Documentos secretos de la ITT, lançado pela Quimantú em 1972 e que gerou forte repercussão na época. O prólogo original, que foi perdido durante a apreensão do livro pelos militares, teria sido escrito no formato de HQs e buscava "relacionar a ideologia que se agitava por trás dos companheiros d'alma do super-herói com as tentativas insurrecionais das classes dominantes, destituídas de poder executivo no Chile". Tal como Gagarito e seus amigos, os autores pressentiam que o Super-Homem "estava em todos os cantos do Chile" e se tornara "o mais perigoso" adversário a ser combatido (DORFMAN; JOFRÉ, 1974, p. 15-16). 
Essa perspectiva orientava a política editorial de Quimantú para outras publicações em quadrinhos, adaptando-se às especificidades de cada gênero narrativo. Em editorial publicado no quinto número de Cabrochico, presente no referido suplemento dirigido aos pais, a equipe responsável pelos quadrinhos na Quimantú buscou apresentar seu ponto de vista a respeito das HQs de terror:

Senhora, seu filho tem medo de alguns animais, não se atreve a encarar uma pessoa desconhecida e tem medo do escuro? Quando foi a primeira para a escola, teve medo de entrar nela?

Não acha que isso [uma ilustração de um dinossauro, sob o título de "Terror"] contribui para aumentar os temores que seu filho possui?

Para que uma história em quadrinhos seja interessante, a senhora considera que é preciso recorrer a tais métodos? Não acha que é melhor criar o suspense com humor e sem utilizar o terror? (CABROCHICO, 1971b, p. 32-33, tradução nossa). ${ }^{3}$

\section{Circularidades culturais: quadrinhos e livros (1960-1970)}

A produção literária que, de alguma forma, operou uma apropriação das HQs em suas narrativas, seja adotando-as como temática principal, seja utilizando suas propriedades gráficas e visuais para problematizar o suporte editorial "livro", teve seu marco fundamental nas décadas de 1960 e 1970. Estes foram anos de discussões em torno do binômio "cultura erudita/cultura de massas", quando nomes conectados às vanguardas literárias próximas ao formalismo ou ao realismo fantástico tomaram as HQs como recursos críticos importantes para suas narrativas. É o que se observa na análise de algumas obras de nomes como Enrique Lihn e Julio Cortázar, e do movimento de poesia brasileira chamado PoemaProcesso, entre outros.

\footnotetext{
${ }^{3}$ No original: "Señora, ¿su hijo le tiene miedo a algunos animales, no se atreve a enfrentarse a una persona desconocida, le tiene miedo a la oscuridad? Cuando fue por la primera vez a la escuela, ¿tuvo temor de entrar en ella? ¿No cree que esto contribuye a aumentar los temores que su hijo tiene? Para que una historieta sea interesante, ¿cree usted que hay que recurrir a estos métodos? ¿No cree que es mejor crear el suspenso con humor y no utilizando el terror?" (CABROCHICO, 1971b, p. 32-33).
} 
A produção literária de Enrique Lihn durante os anos 1970 pode ser analisada a partir dos debates presentes na sociedade chilena acerca do papel a ser assumido pelas artes num contexto de transformação social.

Em documento publicado no final de 1970 pela revista de crítica cultural Cormorán, um grupo de escritores e intelectuais - entre eles Lihn, então diretor da revista, e Ariel Dorfman - defendia que, a partir da chegada ao poder da UP, era necessário que artistas e críticos assumissem a função de "vanguarda do pensamento". Para tal, propunham discussões sobre a superação da condição de "subdesenvolvimento e de dependência" no campo cultural, sugerindo a criação de uma "Corporación de Fomento de la Cultura" e de um "Instituto del Libro y Publicaciones", tendo como norte a crítica à cultura burguesa, então tida como hegemônica (CORMORÁN, 1970, p. 7-9).

Um dos componentes desta cultura burguesa certamente eram os super-heróis. Considerava-se que efetivamente encarnavam a presença imperialista no Chile. Se a sugestão de uma revista simpática ao governo da UP chilena indicava que os super-heróis eram um "lugar de memória" da presença dos EUA no país, sua condição monumental e dominadora e, por redução metonímica, a de todos os cómics - tinha de ser contestada ao nível da narrativa. A saída para tal se deu pela associação entre paródia e política. Esta foi a perspectiva de Ariel Dorfman e Armand Mattelart (1971) no já mencionado Para leer el Pato Donald, com seu diálogo entre marxismo estruturalista francês e a mescla de paródia e ensaio, e também de Lihn em Batman en Chile.

Publicado em junho de 1973, Batman en Chile é uma espécie de HQ narrada em prosa e editada em formato de livro. A obra narra as desventuras do personagem título no Chile em sua atuação como espião da CIA, motivando discussão de temas como a institucionalização das esquerdas, massificação da sociedade, imprensa livre e o clima político do Chile no período. Foi publicada por Ediciones de la Flor, casa editorial argentina conhecida por editar HQs como a série Mafalda, por exemplo, e autores como Cortázar e Umberto Eco. Fica a questão sobre o porquê de não ter sido publicada pela editora próximo à UP, Quimantú.

Talvez a ampla crítica de Lihn ao contexto chileno da época explique o porquê de seu livro não ter sido publicado em Quimantú. Num texto publicado originalmente em maio de 1971 e compilado na coletânea de ensaios El circo en llamas [O circo em chamas], reafirmase a verve crítica e ácida de Lihn (1996), que avalia de forma rigorosa 
a política cultural da Revolução Cubana, encerrando com uma espécie de alerta ao contexto da UP:

A política cultural de Cuba caracterizou-se, durante doze anos, por sua imprecisão teórica e até por sua excessiva flexibilidade prática, mas que atendeu aos propósitos da Revolução. Embora considerasse conveniente ganhar prestígio internacional, não parava de atrair intelectuais dos três mundos; de preferência aqueles a quem Fidel Castro agora chama de "os ratos intelectuais" dessas "sociedades decadentes, podres e podres comidas até a medula dos ossos por suas próprias contradições".

[...]

A aspiração legítima de uma sociedade socialista de criar uma cultura nacional e popular deve ser elevada em termos e de acordo com outros princípios. (LIHN, 1996, p. 432. Tradução nossa). ${ }^{4}$

Quanto à opção por Batman, cabe lembrar que muitos dos personagens da casa editorial Marvel Comics - como Captain America e Iron Man, usualmente associados ao imperialismo norte-americano ainda não eram bem conhecidos no Chile. Por outro lado, Batman era um fenômeno mundial em fins dos 1960, graças em parte à exitosa série televisiva. Havia mesmo uma banda de rock inspirada no personagem, chamada Los Bates.

Porém, Batman é distinto de outros super-heróis como Superman. Batman é inspira-se na literatura de detetive e na estética noir. Sua humanidade se expressa na sua história de origem, marcada pelo sentimento de vingança pela morte de seus pais, e no seu combate ao crime, possível graças à sua inteligência. Sua humanidade viabiliza a desconstrução do mito, estimulada pelas condições da realidade chilena, muito distintas da norte-americana. Citamos Daniel Pacha, que discute usos literários de elementos próximos à linguagem das HQs na obra:

\footnotetext{
${ }^{4}$ No original: "La política cultural de Cuba se caracterizó, durante doce años, por su indefinición teórica y una flexibilidad práctica hasta excesiva, pero que servía a los fines de la Revolución. Mientras esta juzgó conveniente prestigiarse internacionalmente, no dejó de atraer a los intelectuales de los tres mundos; de preferencia a los que ahora llama Fidel Castro, 'las ratas intelectuales' de 'esas sociedades decadentes, podridas y carcomidas hasta la médula de los huesos por sus propias contradicciones'. [...] La legítima aspiración por parte de una sociedad socialista, de crear un cultura nacional y popular, debe plantearse en potros términos y conforme a otros principios" (LIHN, 1996, p. 432).
} 
A realidade torna-se um pesadelo para um personagem que acaba oprimido por seu excesso de pragmatismo. Por exemplo, a imitação que Lihn faz em sua escrita, dos cartuchos como frases tópicas que permitem diálogos internos dos personagens ou marcações temporais como reticências, flashbacks, raccontos ou flashforwards e, claro, mudanças de cenário entre vinhetas: 'enquanto isso' ou 'em outro lugar da cidade' parecem ser destinados apenas para Batman e não para aqueles ao seu redor, de modo que seu sonho de mundos impossíveis nunca mais retornará à simplicidade do sonho americano, hoje impossível de habitar. (PACHA, 2015, p. 55. Tradução nossa) $)^{5}$

A associação entre vanguarda, crítica política e HQs também se desenvolveu no Brasil, mas por meio da poesia. Um dos mais destacados pesquisadores de HQs no Brasil foi Moacy Cirne. Cirne atuou como editor da Revista de Cultura Vozes durante a década de 1960, contribuindo para aproximá-la aos debates em torno de temas como estruturalismo e semiótica. Reconhecido pesquisador de HQs no Brasil, dialogou com as leituras críticas sobre o tema produzidas na França, que buscavam dotálas de legitimidade cultural (LAFARGUE, 2012). De perfil iconoclasta, para defender as HQs brasileiras afirmava sem medo que "entre um poema de [Carlos] Drummond [de Andrade] e uma estória qualquer do Pererê, optamos pela estória de Pererê" (CIRNE, 1975). Próximo a leituras marxistas, nacionalistas e críticas ao imperialismo dos EUA, a perspectiva de Cirne integra uma crítica à ditadura militar brasileira (1964-1985) através de uma defesa das HQs brasileiras como contraponto à indústria dos comics norte-americanos, ao mesmo tempo em que parte da linguagem das HQs para propor caminhos rumo a uma vanguarda poética própria do Brasil.

Cirne participou da fundação, das principais atividades e integrou sua reflexão acerca das HQs às do movimento de vanguarda literária

\footnotetext{
${ }^{5}$ No original: "La realidad se vuelve una pesadilla para un personaje que termina superado por su exceso de pragmatismo. Por ejemplo, la imitación que Lihn hace en su escritura, de los cartuchos a manera de frases tópicas que permiten diálogos internos de los personajes o marcaciones temporales como elipsis, flash backs, raccontos o flash forwards y desde luego cambios de escenario entre viñetas: 'mientras tanto' o 'en otro lugar de la ciudad', parecen estar destinados sólo a Batman y no a quienes lo rodean, de modo que su sueño de mundos imposibles jamás retornará a la simpleza del sueño americano, hoy imposible de habitar" (PACHA, 2015, p. 55).
} 
chamado Poema Processo, as quais se seguiram de 1967 a 1972. Liderado pelos poetas Wlademir Dias-Pino e Álvaro de Sá, tinha como orientação a defesa da radicalização das noções concretistas apresentadas ao público na década anterior pelos irmãos Campos e Décio Pignatari. O interesse passava a ser na experimentação com os signos e a linguagem, superando o que considerava como uma falsa dicotomia significante/significado e que estaria presente nas realizações concretistas. O movimento seria também distinto da pop art, cujos trabalhos traziam "resultados bastante discutíveis" em termos estéticos, mais parecendo uma "revista tamanho família" e uma "mera cópia ampliada" do trabalho de outros artistas (CIRNE, 1970, p. 64-66).

Por fim, mencionemos um terceiro nível de trânsitos intermidiáticos entre literatura e HQs. O escritor argentino, Julio Cortázar, publicou, em 1975, a obra Fantomas contra los vampiros multinacionales, no México, pela editoria Excelsior. A obra foi lançada originalmente como uma revista em quadrinhos, tomando como referência Fantômas, personagemtítulo da literatura popular francesa do início do século XX. Porém, no México e em parte da América Latina, o personagem se tornou mais conhecido no pós-Segunda Guerra Mundial através de sua versão de revista de HQs, intitulada Fantomas, la Amenaza Elegante (1966-1985). Nela, o personagem supera as características originais do personagem e assume perfil híbrido: é um pouco de super-herói, de James Bond, de Robin Hood e carrega alguma pretensão intelectual. Numa HQ em especial, Fantomas deve impedir que um desconhecido roube e destrua todos os livros do mundo. Para tal, busca ajuda dos escritores Alberto Moravia, Octavio Paz, Susan Sontag, e do próprio Cortázar. Quando avisado sobre a revista, Cortázar a lê e decide produzir outra revista em quadrinhos protagonizada por Fantomas, desta vez apontando que o "bibliocídio" que investigara não se devia tanto a uma espécie de lunático, mas sim à cultura imperialista das grandes corporações multinacionais.

Quando é avisado sobre a revista, Cortázar a lê e chega à seguinte conclusão:

[...] senti que Fantomas, com toda sua inteligência e energia, havia cometido um erro no cartoon dos livros queimados. Pareceu-me que era muito fácil atribuir esse bibliocídio em grande escala a um mero louco, e que forças ocultas deveriam ter posto Fantomas numa pista falsa ou, pelo menos, incompleta. Quase ao mesmo tempo disse a mim mesmo que era meu dever auxiliá-lo e explicar 
o que me parecia ser a verdade. Mas como fazer isso? Como chegar até Fantomas? A resposta era óbvia: por meio de outra história em quadrinhos, já que era o único terreno comum entre ele e eu. (CORTÁZAR, 2009, p. 462. Tradução nossa). ${ }^{6}$

A obra integra diversos recursos visuais para além da HQ, como fotografias e colagens, aproveitando-se do perfil técnico e dinâmico das HQs para promover uma obra próxima à ideia de "palimpsesto", de Genette (1982), ou seja, um texto como reescritura de textos anteriores, dialogando com eles sem silenciá-los e ampliando a gama de relações entre cada um, conforme defende Gutiérrez (2016, p. 95). As apropriações da linguagem, articulando técnica e estética, proporcionam questões para a própria ideia de autoria. É o que sugere o próprio Cortázar, numa entrevista não por acaso de perfil explicitamente ficcional:

- Há rumores nos meios cultos - disse Polanco - que seu novo livro é heterodoxo, anfíbio, ilustrado e a cores.

- Não é um livro - faço-lhe notar - e sim uma simples história em quadrinhos, isso que chama de tiras cômicas ou muñequitos [denominação cubana para HQs], com alguns modestos adendos de minha parte.

- Então agora você desenha e tudo?

- Não, retirei os desenhos de uma HQ de Fantomas.

- Um roubo, então. Como de costume.

- Não senhor, nessa HQ Fantomas falava de mim, e nesta eu falo de Fantomas.

- Digamos que é uma espécie de plágio.

- Também não, amigo. Se eu puder falar dois minutos, explicarei tudo (CORTÁZAR, 2009, p. 460). ${ }^{7}$

6 “[...] sentí que Fantomas, con toda su inteligencia y energía, se había equivocado en la historieta de los libros quemados. Me pareció que resultaba demasiado fácil atribuir ese bibliocidio en gran escala a un mero demente, y que fuerzas disimuladas habían debido poner a Fantomas sobre una pista falsa, o en todo caso incompleta. Casi simultáneamente me dije que mi deber era acudir en su ayuda y explicarle lo que me parecía la verdad. ¿Pero cómo hacerlo? ¿Cómo llegar hasta Fantomas? La respuesta era obvia: por medio de otra historieta, puesto que era el único terreno común entre él y yo" (CORTÁZAR, 2009, p. 462). 7 "Se rumorea en los medios cultos -dice Polanco- que tu nuevo libro es heterodoxo, anfibio, ilustrado y en colores./ -No es un libro- le hago notar -sino una simple historieta, eso que llaman tiras cómicas o muñequitos. con algunos modestos agregados de mi parte./ -¿Así que ahora dibujas y todo?/ -No, los dibujos los saqué de una 
Tudo isso, novamente, com forte orientação política. A obra segue com o tom crítico em torno da presença norte-americana na América Latina, como sugerido também em Lihn.

\section{Conclusão}

As transformações nas HQs ocorreram em ritmos diferentes ao redor do globo, resultado das transformações técnicas advindas da Segunda Revolução Industrial. Artistas que dominavam processos gráficos ligados ao humor gráfico do século XIX - como litografia, por exemplo - viram-se inclinados a agregar novas soluções visuais ao seu manancial criativo por meio dos novos elementos técnicos e sociais que surgiam na cena. A popularização da impressão em quatro cores e do modelo offset, por exemplo, permitiu a criação de trabalhos ricos em cores e a integração dinâmica de textos e imagens.

As HQs são uma prática cultural construída socialmente ao longo do tempo. Suas modificações formais, portanto, são históricas e atendem a questões internas e externas ao seu material. Ressalta-se o caráter essencialmente paratextual de uma linguagem gráfica como as HQs, conferido pela sua condição material (BREDEHOFT, 2014). Isso quer dizer que os quadrinhos, tal como toda prática cultural, devem ser discutidos como uma atividade que, construída socialmente por meio de modos de ler e ver historicamente localizados, termina também por problematizar ativamente o seu tempo de forma original e heterogênea.

Criar uma HQ implica dialogar com uma série de práticas já desenvolvidas no mundo dos quadrinhos, num processo de mediação cultural envolvendo editores, artistas e consumidores, entre outros agentes. Destaca-se, pois, a especificidade das práticas culturais: o que é produzido não responde apenas a determinações econômicas, mas também a demandas culturais socialmente construídas. Em resumo, refletir sobre as publicações de quadrinhos como um diálogo com a "trama cultural e os modos de ver" de seus leitores pode contribuir para uma análise histórica e menos essencialista dessa linguagem.

historieta de Fantomas./ -Un robo, entonces, como de costumbre./ -No señor, en esa historieta Fantomas se ocupaba de mí, y en ésta yo me ocupo de Fantomas./ -Digamos una especie de plagio./ -Tampoco, che. Con que me dejen abrir la boca dos minutos, les explico la cosa" (CORTÁZAR, 2009, p. 460). 
Chama atenção a ausência de abordagens que cruzem contextos latino-americanos, de forma a reconstituir a trajetória dos quadrinhos na região. A esta altura é possível concluir que a história visual e editorial das HQs na América Latina, marcada pelos embates entre a produção local e a importação de material estrangeiro, ainda está por ser contada. As HQs ultrapassam as divisas nacionais, tal como os personagens ultrapassam as fronteiras dos quadrinhos e alcançam o cotidiano das pessoas sob a forma de produtos e fantasias. É possível compreendê-las como dotadas de uma "vida social", o que implica abordá-las a partir da circulação de sentidos e práticas que ultrapassam fronteiras historicamente estabelecidas, como as do Estado-nação, por exemplo. Como conclusão, as HQs se constituem como prática cultural por meio das circulações e apropriações de sentidos presentes nas diferentes interações entre tais escalas de análise, o que aponta para uma história transnacional dos quadrinhos.

\section{Referências}

ADAMS, Thomas; BARKER, Nicolas. A New Model for the Study of the Book. In: BARKER, N. (org.). A Potencie of Life: Books in Society. London: British Library, 1993. p. 5-43.

BREDEHOFT, Thomas. The Visible Text: Textual Production from Beowulf to Maus. Oxford: Oxford University Press, 2014.

CABROCHICO. Santiago de Chile, Quimantú, n. 3, 1971a.

CABROCHICO. Santiago de Chile, Quimantú, n. 5, 1971 b.

CAGNIN, Antônio. Angelo Agostini - uma pesquisa. Nona Arte, São Paulo, v. 2, n. 2, p. 53-73, 2013. Disponível em: http://www.revistas. usp.br/nonaarte/article/view/136871/132621. Acesso em: 25 out. 2020.

CHARTIER, Roger. Do livro à leitura. In: (org.). Práticas de leitura. 5. ed. Tradução de Cristiane Nascimento. São Paulo: Estação Liberdade, 2011. p. 77-105.

CIRNE, Moacy. Bum! A explosão criativa dos quadrinhos. Petrópolis: Vozes, 1970.

CIRNE, Moacy. A linguagem dos quadrinhos: o universo estrutural de Ziraldo e Maurício de Sousa. 4. ed. Petrópolis, Rio de Janeiro: Vozes, 1975. 
CORMORÁN. Santiago de Chile, Editorial Universitaria, v. 1, n. 8, dez. 1970.

CORTÁZAR, Julio. Papeles inesperados. Santillana: Alfaguara, 2009.

CRARY, Jonathan. Técnicas do observador. Rio de Janeiro: Contraponto, 2012.

DARNTON, Robert. O beijo de Lamourette: mídia, cultura e revolução. Tradução de Denise Bottmann. São Paulo: Companhia das Letras, 1990.

DARNTON, Robert. "O que é a história do livro?" Revisitado. ArtCultura, Uberlândia, v. 10, n. 16, p. 155-169, jan.-jun. 2008. Disponível em: http:// www.seer.ufu.br/index.php/artcultura/article/view/1503/2758. Acesso em 25 out. 2020.

DORFMAN, Ariel; MATTELART, Armand. Para leer al pato Donald. Valparaíso: Ediciones Universitarias de Valparaíso, 1971.

DORFMAN, Ariel; JOFRÉ, Manuel. Supermán y sus amigos del alma. Buenos Aires: Editorial Galerna, 1974.

EFRAÍN GRANADOS, Daniel. Charros, chinos y aboneros: estereotipos, nacionalismo y xenofobia en el humorismo gráfico de El Universal. 2013. 214f. Tese (Licenciatura em História) - Colegio de Historia, Universidad Autónoma de México, México D.F., 2013.

EISNER, Will. Comics and Sequential Art. Tamarac: Poorhouse Press, 1985.

EISNER, Will; MILLER, Frank; BROWNSTEIN, Charles. Eisner/ Miller: uma entrevista cara a cara conduzida por Charles Brownstein. Tradução de Ren Ferri. São Paulo: Criativo, 2004.

ESPAGNE, Michel. La notion de transfert culturel. Revue Sciences/ Lettres, Paris, n. 1, 2013. DOI: https://doi.org/10.4000/rsl.219. Disponível em: http://journals.openedition.org/rsl/219. Acesso em 30 ago. 2020.

GABILLIET, Jean-Paul. 'Fun in four colors': comme la quadrichromie a créé la bande dessinée aux États-Units. Transatlantica, [S.l.], v. 4, p. 1-8, 2005. DOI : https://doi.org/10.4000/transatlantica.319. Disponível em: https://journals.openedition.org/transatlantica/319. Acesso em 30 ago. 2020 . 
GARCÍA, Fernando; ROCCA, Hernán. Tangos de historietas. Revista Latinoamericana de Estudios sobre la Historieta, Habana, v. 3, n. 11, p. 125-136, 2003. Disponível em: http://rlesh.mogno.com/11/11_garcia. html. Acesso em 25 out. 2020.

GENETTE, Gérard. Palimpsestes. La littérature au second degré. Paris: Seuil, 1982.

GOMES, Ivan L.; GONCALVES, Roberta F. Imagens de uma República infantil: Angelo Agostini nas revistas $O$ Malho e $O$ Tico-Tico. Revista Maracanan, Rio de Janeiro, v. 12, n. 14, p. 225-240, 2016. DOI: https:// doi.org/10.12957/revmar.2016.20871.

GOMES, Ivan L. Angelo Agostini e os quadrinhos: algumas questões. In: RODRIGUES, M.; CALLARI, V. (org.). História e quadrinhos: contribuições ao ensino e à pesquisa. Belo Horizonte: Letramento, 2021. [no prelo].

GONÇALVES, Roberta. F. Uma aventura na América: a trajetória do personagem Chiquinho, dos Estados Unidos até o Brasil. In: VENÂNCIO, Giselle Martins (org.). Histórias no singular: textos, práticas \& sujeitos. Curitiba: Appris, 2019. p. 17-36.

GUTIÉRREZ, Julio. Julio Cortázar's, 'Fantomas contra los vampiros multinacionales': from sequential rhetoric to literary blending. Image and Narrative, Leuven, v. 17, n. 3, p. 86-97, 2016. Disponível em: http://www. imageandnarrative.be/index.php/imagenarrative/article/view/1291/1045. Acesso em 25 out. 2020.

JOFRÉ, Manuel. La historieta en Chile en la última década. Santiago: CENECA, 1983.

LAFARGUE, Jean-Nöel. Entre la plèbe \& l'élite: Les ambitions contraires de la bande dessinée. [S.l.]: Atelier Perrousseaux, 2012.

LEFÉVRE, Pascal. The Battle Over the Balloon. Image and Narrative, Leuven, v. 7, n. 14, 2006. Disponível em: http://www.imageandnarrative. be/inarchive/painting/pascal_levevre.htm. Acesso em 25 out. 2020.

LIHN, Enríque. El circo en llamas. Santiago: LOM, 1996.

MARINGONI, Gilberto. Angelo Agostini: a imprensa ilustrada da Corte à Capital Federal, 1864-1910. São Paulo: Devir Livraria, 2011. 
MATTELART, Armand. La dependencia de los medios de comunicación de masas en Chile. Estudios Internacionales, Santiago, v. 4, n. 13, p. 124-154, 1970. DOI: https://doi.org/10.5354/0719-3769.1970.18916. Disponível em: https://revistaei.uchile.cl/index.php/REI/article/ view/18916/20035. Acesso em: 26 out. 2020.

MCCLOUD, Scott. Understanding Comics. New York: Harper Perennial, 1994.

MCLUHAN, Marshall. The Gutenberg Galaxy: The Making of Typographic Man. Toronto: University of Toronto Press, 1962.

MOLLIER, Jean-Yves. A leitura e seu público no mundo contemporâneo. Tradução de Elisa Nazarian. Belo Horizonte: Autêntica, 2008.

MONTEALEGRE, Jorge. Historia del humor gráfico en Chile. Lleida: Editorial Milenio, 2008.

O TICO-TICO, Rio de Janeiro, n. 1408, 28 set. 1932. Disponível em: http://memoria.bn.br/pdf/153079/per153079_1932_01408.pdf. Acesso em 30 ago. 2020.

PACHA, Daniel. Batman en Chile o la deformación histriónica de un mito. Aisthesis, Santiago, n. 57, p. 43-57, 2015. DOI: https://doi. org/10.7764/ais.57.43-57. Disponível em: https://scielo.conicyt.cl/pdf/ aisthesis/n57/art03.pdf. Acesso em 26 out. 2020.

SILVEIRA, Guilherme. Os balões n'O Tico-Tico: esqueceram de desenhar? Revista História, Movimento e Reflexão, Dourados, v. 1, n. 1, 2013.

SMOLDEREN, Thierry. Naissances de la bande dessinée: de William Hogarth à Winsor McCay. Bruxelas: Les Impressions Nouvelles, 2009. 